\title{
India's Obsession with Skin Fairness and Whitening: Why?
}

\section{Chytra V Anand*}

Cosmetic Dermatologist, Kosmoderma Clinics, India

The obsession with Fairness and Skin Whitening is not only in India but majority of the South East Asian Countries...

To understand this better, it dates way back to the Vedic Times, where Apsaras (beautiful maidens, usually sent to lure men/distract men from their purposes) they are referred to as beautiful, supernatural female beings. They are youthful and elegant, and superb in the art of dancing and were described as fair skinned maidens. Whereas the evil women/Villains were described as being dark skinned.

In the ancient dynastic times, especially in hot climates, being fair meant being privileged, wealthy and noble and remaining indoors as the labor class had more melanin count due to labor outside [1]. This was propagated during the British rule in India, where they subscribed to caste system that was prevalent in India, where upper caste typically had fairer skin and did not indulge in outdoor activities.

In Indian culture, colorism is taught to children in the form of fairy tales, just as the Grimms' fairy tales featured light-skinned princesses or maidens; Indian mythological protagonists are typically fair and depict beauty, virtue, purity, and goodness.

Among children, it is rampant to see the fairer child being complimented more as being fair and lovely rather than for other accomplishments [2].

The same is experienced in the social setting of a wedding, where the commonest compliment and possibly the highest a bride gets is she is so fair and lovely.

This color bias extends to the working environment too. A while back in one of the western states, 100 tribal girls were given vocational training to be air hostesses/cabin crew and they passed the exams, but during the interview only 8 were offered the role of ground staff due to their dark skin color. The tribal population in India is typically dark colored with Fitzpatrick Skin type 5/6 [3].
This colorism/bias or desire for fairness and skin lightening is increased due to exposure to western \& Indian media that sets the standards of skin color through their adverts and infomercials. Adding to this are powerhouse skincare brands with their constant advertising that being fair is prestigious and to be desired.

In India, the fairness market is estimated to be worth $\$ 450$ million USD... Every brand like Unilever, Dove, Nivea, Pond's, Garnier, Neutrogena, Olay, Himalaya has a skin lightening range on the shelves today catering to the women and to men, the newer growing segment in the fairness market [4].

In fact, in 2014, according to consumer surveys, $65 \%$ of Indian women used a skin lightening cream.

From this there has been a surge in skin lightening procedures at salons and doctors offices, with all beauty clinics offer de tan and lightening procedures.

In Summary, light complexion is equated with beauty, racial superiority, and power, and has strong influences on marital prospects, employment, income and social status [5].

This is why not just India but South East Asia is obsessed with being fair.

\section{Refrences}

1. CNN (2002) Skin Deep: Dying to be White".

2. Das V (2012) FAIR? A Documentary about Skin-Colour in India.

3. Sonawane R (2008) "Tribal girls trained as air hostesses: Govt plan crashlands".

4. Savastio R (2014) Which Major Cosmetic Brands Say White Skin is More Beautiful and Perfect Than Dark Skin? All of Them". Guardian Liberty Voice.

5. Verma HV (2011) Skin 'fairness'-Culturally Embedded Meaning and Branding Implications. Global Business Review.
*Corresponding author: Chytra V Anand, Kosmoderma Dermatology, 67/2 Lavelle Road, Bangalore, Karnataka, 560001, India, Tel: 919900075767; E-mail: dr.chytra@gmail.com

Received January 21, 2016; Accepted April 04, 2016; Published April 11, 2016

Citation: Anand CV (2016) India's Obsession with Skin Fairness and Whitening: Why? Pigmentary Disorders 3: 241. doi: 10.4172/2376-0427.1000241

Copyright: (C) 2016 Anand CV. This is an open-access article distributed under the terms of the Creative Commons Attribution License, which permits unrestricted use, distribution, and reproduction in any medium, provided the original author and source are credited. 